Ann. Biol. anim. Bioch. Biophys., I969, 9 (2), 139-160.

\title{
UTILISATION DIGESTIVE DES MATIÈRES GRASSES ET DE LEURS PRINCIPAUX ACIDES GRAS PAR LE VEAU PRÉRUMINANT A L'ENGRAIS. INFLUENCE SUR LA COMPOSITION CORPORELLE
}

\author{
R. TOULLEC et C.-M. MATHIEU
}

avec la collaboration technique de Jeanne BARdy, Jacqueline Rigaud et C. MarpiLlat

\author{
Station de Recherches sur l'Élevage des Ruminants, \\ Centre de Recherches zootechniques et vétérinaires sur les Ruminants, \\ 63 - Theix, près Clermont-Ferrand \\ Institut national de la Recherche agronomique
}

\section{SOMMAIRE}

Le but de cet essai a été d'étudier, chez le veau préruminant, l'utilisation digestive des matières grasses en fonction de leur composition en acides gras et de leur structure glycéridique. Cinq matières grasses (suif, saindoux, huiles d'arachide, de coprah et de palme) ont été introduites dans du lait écrémé liquide à raison de $20 \mathrm{p}$. 100 de la matière sèche et les mélanges ainsi obtenus ont été homogénéisés, puis séchés par le procédé Spray. Les laits préparés à partir de ces aliments d'allaitement ont été comparés, d'une part, à du lait partiellement écrémé ayant la même teneur en matières grasses (25 p. I 00o) et, d'autre part, à du lait totalement écrémé (moins de I p. I 000 de matières grasses) donc pratiquement lipidoprive. Ces aliments ont été distribués à $\mathrm{I} 3$ veaux mâles de race Frisonne (2 veaux par régime sauf pour le lait à $25 \mathrm{p}$. I ooo qu'un seul animal a reçu), maintenus en cage à bilan entre les âges de 8 et 95 jours. Les veaux ont reçu des quantités de lait importantes, comparables à celles qui sont habituellement offertes aux veaux à l'engrais.

Les veaux alimentés au lait écrémé excrètent une quantité d'acides gras très faible $(0,3 \mathrm{à} 2 \mathrm{~g} / \mathrm{j})$ qui ne varie ni avec l'âge, ni avec la quantité d'aliment ingérée mais augmente significativement avec la fréquence des diarrhées.

La digestibilité apparente des matières grasses est très élevée : suif go p. ıoo, huile d'arachide 93, huile de palme 95, huile de coprah et saindoux 96 et matières grasses du lait 98 . La digestibilité apparente est pratiquement totale pour les acides gras courts $<\mathrm{C}_{12}$; elle diminue ensuite, pour les acides gras saturés, avec l'allongement de la chaîne et, pour une même longueur de chaîne, elle augmente avec le degré d'insaturation. L'acide palmitique semble mieux utilisé quand il se trouve en position interne dans les molécules de triglycérides (saindoux). L'insaturation élevée augmente la fréquence des diarrhées et se montre défavorable à la croissance (huile d'arachide). Le principal facteur déterminant l'utilisation digestive des matières grasses étudiées est leur teneur en acides gras longs saturés $>\mathrm{C}_{10}$.

La composition en acides gras des graisses corporelles, en particulier leur teneur en acides gras insaturés, est nettement influencée par celle des matières grasses alimentaires. En revanche, les acides gras courts et moyens $<\mathrm{C}_{12}$ ne sont pratiquement pas déposés. Le veau préruminant se comporte donc à cet égard comme un monogastrique.

Les matières grasses riches en acides gras courts devraient favoriser la croissance au début de la vie du veau d'autant plus qu'elles ont alors une utilisation digestive plus élevée que les matières grasses ne contenant que des acides gras longs et saturés ; en revanche, ces dernières devraient ensuite favoriser l'engraissement. 


\section{INTRODUCTION}

Le veau à l'engrais qui est maintenu au stade préruminant, ne doit recevoir que du lait ou des aliments d'allaitement. Ces derniers sont constitués de lait écrémé (70 à 80 p. IOo) et de matières grasses ( 15 à 25 p. IOO) dont le suif est la plus couramment employée en France.

Depuis que HAECKER en Igo5 a introduit de 1'huile de maïs dans du lait écrémé pour augmenter sa valeur énergétique, 1'utilisation digestive de nombreuses matières grasses a été étudiée par différents auteurs (FINGERLING, I908; CuNNINGHAu et Loosir, I954 ; RAVEN et RoBINSON, I958-I959-I960 ; THOMKE, I963) qui ont trouvé des CUD apparents élevés et variables (tabl. I). En général, ces études ont été fragmentaires, de courte durée et n'ont été effectuées que sur des veaux recevant des quantités limitées de lait et réalisant des croissances faibles ; aucun auteur n'a \&nvisagé systématiquement 1'utilisation digestive des matières grasses en fonction de leur structure glycéridique et de leur composition en acides gras.

C'est ce que nous nous sommes proposés ici en mesurant la digestibilité de cinq matières grasses (suif, saindoux, huiles d'arachide, de coprah et de palme) introduites dans des aliments d'allaitement à raison de $20 \mathrm{p}$. Ioo de la matière sèche. Nous avons distribué les laits de remplacement obtenus à partir de ces aliments d'allaitement à' des veaux maintenus en cage à bilan entre les âges d'environ 7 et roo jours. Les quantités distribuées étaient comparables à celles qui sont habituellement offertes aux veaux à l'engrais. Nous avons mesuré la digestibilité apparente des laits et de leurs' différents constituants, en particulier celle des principaux acides gras. Ces laits ont été comparés d'une part, à du lait partiellement écrémé ayant la même teneur en matières grasses (25 p. I ooo) que ces laits de remplacement et, d'autre part, à du lait totalement écrémé (moins de I p. I ooo de matières grasses) donc pratiquement lipidoprive.

\section{MATÉRIEL ET MÉTHODES}

\section{Aliments}

La composition en acides gras des matières grasses utilisées est reportée dans la figure I. Ces matières grasses ont été retenues pour les raisons suivantes :

- le suif, pour sa richesse en acides gras longs et saturés, particulièrement en acide stéarique ;

- l'huile d'arachide, parce qu'elle contient surtout des acides gras longs mais insaturés ;

- l'huile de coprah, pour sa grande richesse en acides gras courts et moyens ;

- l'huile de palme, parce qu'elle est très riche en acide palmitique et ne renferme que très peu d'acide stéarique ;

- le saindoux, pour la structure particulière de ses triglycérides mixtes (acide palmitique préférentiellement en position interne d'après Savary, Flanzy et DESNUElLe, 1957 et MATTSON et LUTTON, I958).

Ces matières grasses ont été comparées à celles du lait, à laquelle les différents auteurs s'accordent à reconnaître une digestibilité particulièrement élevée (cf. MATHIEU et BARRÉ, I964). Les matières grasses du lait sont originales, car elles contiennent des acides gras de longueur de chaîne très différente (de $\mathrm{C}_{4} \grave{\text { a }} \mathrm{C}_{18}$ ) et possèdent une structure glycéridique caractéristique, voisine de celle du saindoux (acide palmitique préférentiellement en position interne dans les triglycérides de poids moléculaire élevé d'après Dimick, Mc CaRTy et Patton, ig65). 
UTILISATION DES MATIÈRES GRASSES PAR IE VEAU

\begin{tabular}{|c|c|c|c|c|c|c|c|}
\hline \multirow{9}{*}{ 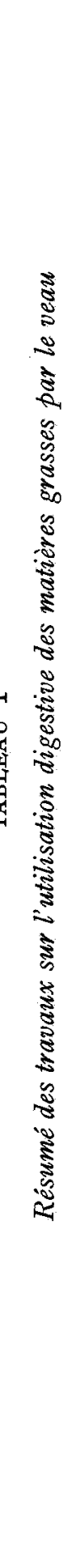 } & 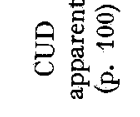 & 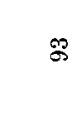 & $\infty$ & $\infty$ & 8.85 & $\infty$ & 疋 \\
\hline & 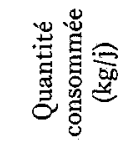 & $\stackrel{\circ}{2}$ & 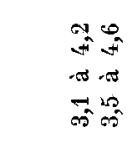 & 3 & 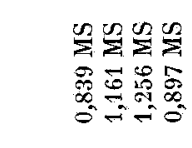 & 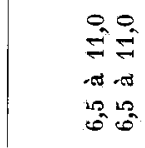 & \\
\hline & 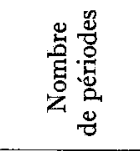 & $r$ & $\stackrel{90}{\rightarrow}$ & 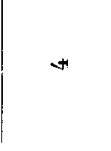 & 녹요곡 & $\stackrel{\infty}{\rightarrow}$ & $\rightarrow \sin 4$ \\
\hline & 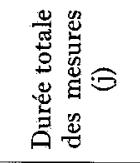 & $\stackrel{2}{\rightarrow}$ & $\delta \infty$ & ت & 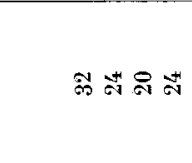 & ร. & సే \\
\hline & 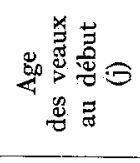 & जิ & $\stackrel{12}{7}=$ & $\infty$ & 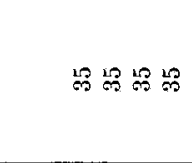 & $\stackrel{12}{2} \stackrel{12}{7}$ & 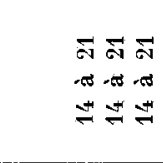 \\
\hline & 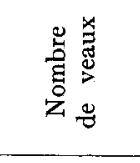 & - & תח מת & $\Leftrightarrow$ & $+\infty+\infty$ & 00 & th is 4 \\
\hline & 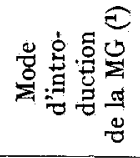 & 蒫 & 되 & 堂 & & & 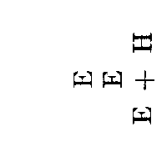 \\
\hline & 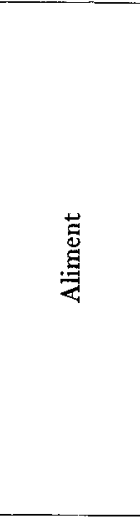 & 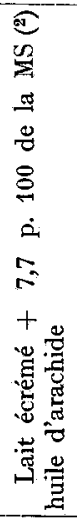 & 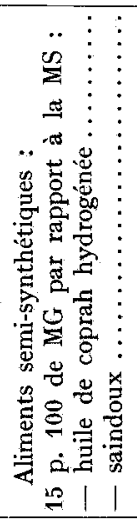 & 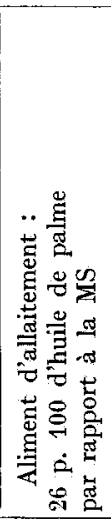 & 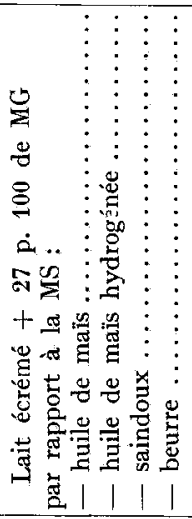 & 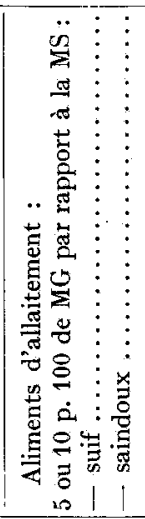 & 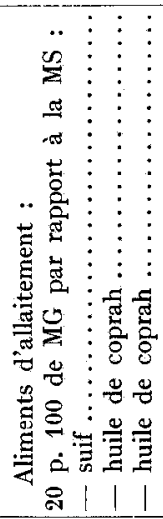 \\
\hline & 峞 & 总 & 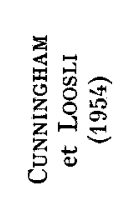 & 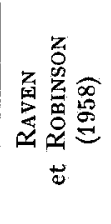 & 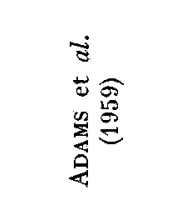 & 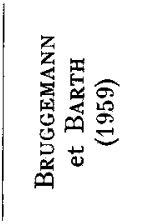 & 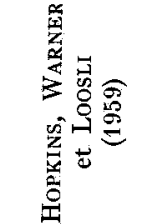 \\
\hline
\end{tabular}


R. TOULLEC, C.-M. MATHIEU

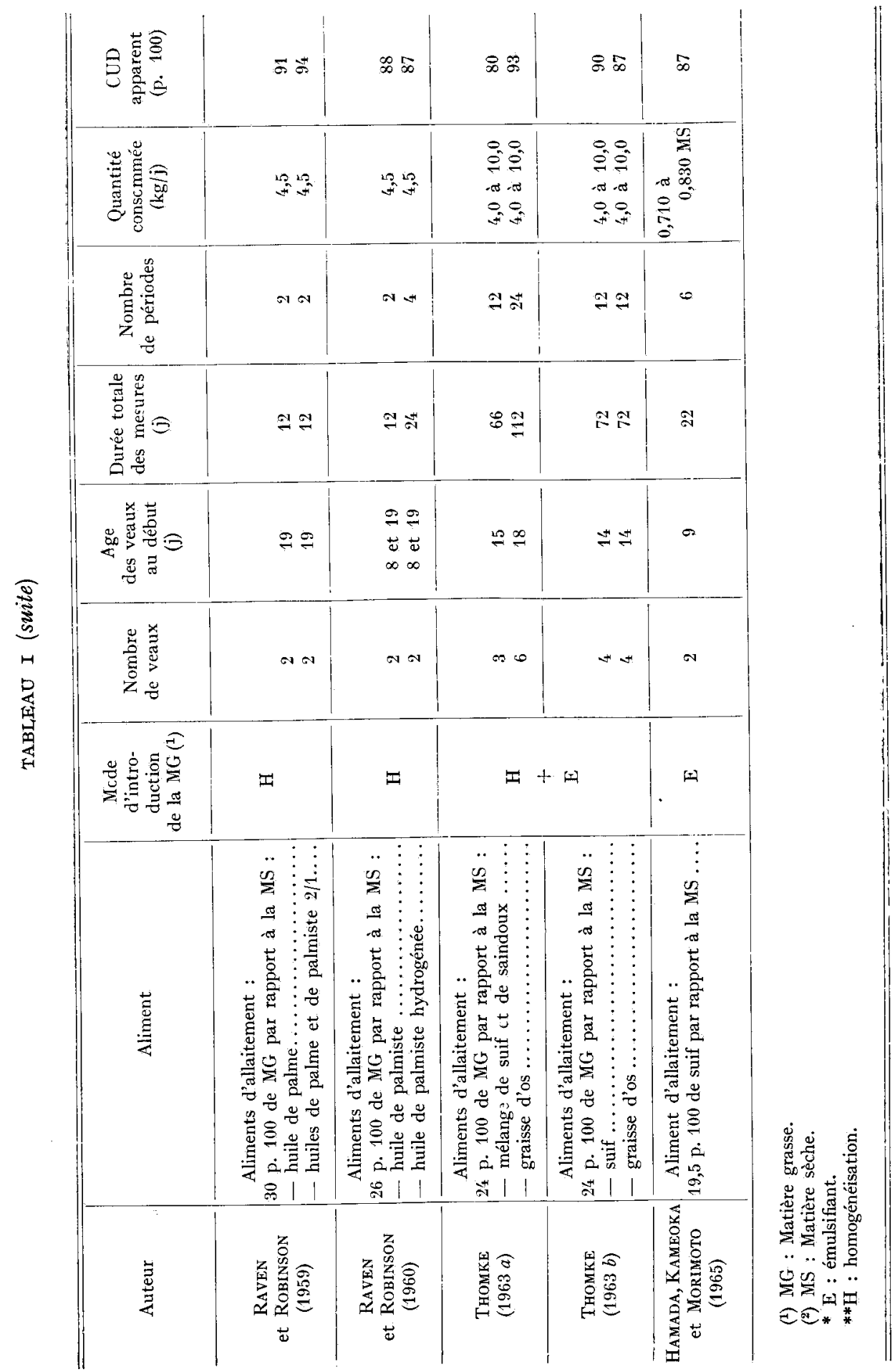



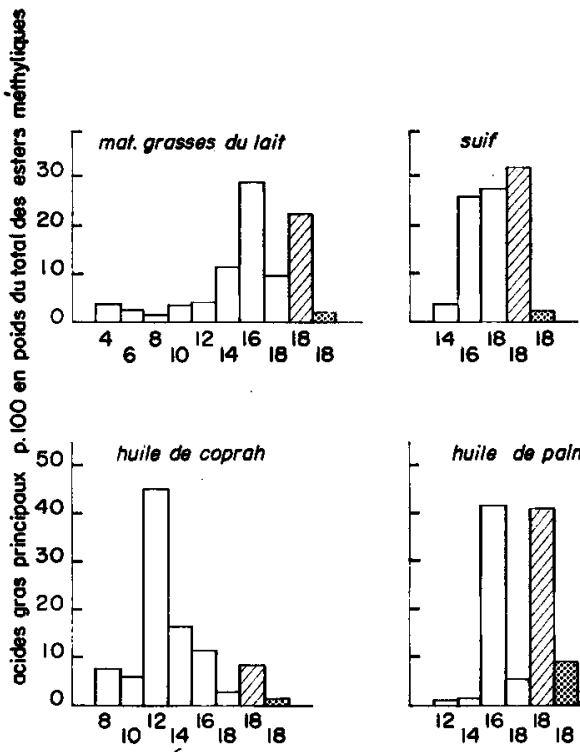

huile d'arachide
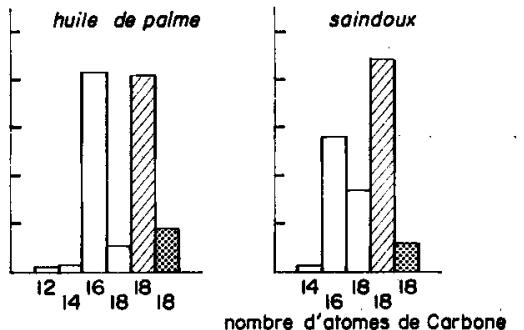

Fig. I, - Composition en acides gras des matieres grasses des aliments

ocides gras soturés
acides monoinsoturés
acides diinsofurés

TABLEAU 2

Composition chimique des aliments

\begin{tabular}{|c|c|c|c|c|c|}
\hline & \multirow{2}{*}{ Aliment } & \multicolumn{3}{|c|}{ Composition (p. 100 de la matière sèche) } & \multirow{2}{*}{$\begin{array}{l}\text { Énergie brute } \\
\text { (kcal/kg de MS) }\end{array}$} \\
\hline & & Matières grasses & Matières azotées & Matières minérales & \\
\hline \multicolumn{2}{|c|}{ Lait écrémé............. } & 0,3 & 39,9 & 8,1 & 4392 \\
\hline \multicolumn{2}{|c|}{ Lait à 25 p. $1000 \mathrm{MG} \ldots$} & 20,8 & 29,9 & 6,1 & 5331 \\
\hline \multirow{5}{*}{ 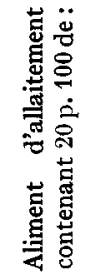 } & Suif $\ldots \ldots \ldots \ldots$ & 20,2 & 27,8 & 6,0 & 5269 \\
\hline & Huile d'arachide. & 19,6 & 30,1 & 6,3 & 5264 \\
\hline & Huile de coprah.. & 19,6 & 30,8 & 6,5 & 5267 \\
\hline & Huile de palme.. & 17,4 & 30,1 & 6,7 & 5160 \\
\hline & Saindoux.... & 20,1 & 25,9 & 6,1 & 5213 \\
\hline
\end{tabular}

Complément vitaminisé (par $100 \mathrm{~kg}$ d'aliment d'allaitement) :
Vitamine A.............. 1200000 UI
$-\mathrm{D}_{3} \ldots \ldots \ldots \ldots \ldots \ldots 60000 \mathrm{UI}$

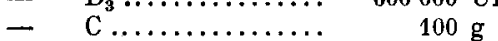
Choline................ $180 \mathrm{~g}$
$-B_{1} \ldots \ldots \ldots \ldots \ldots \ldots . \quad 200 \mathrm{mg}$
Acide pantothénique......... $200 \mathrm{mg}$
- $\mathrm{B}_{2} \ldots \ldots \ldots \ldots \ldots \ldots . . \ldots 00 \mathrm{mg}$
- $\mathrm{B}_{6} \ldots \ldots \ldots \ldots \ldots \ldots . \quad 200 \mathrm{mg}$
$-\mathrm{B}_{12} \ldots \ldots \ldots \ldots \ldots \ldots . \quad 5 \mathrm{mg}$
Biotine .............. $75 \mathrm{mg}$
Furazolidone ............ $5 \mathrm{~g}$ 
La composition des différents aliments est reportée dans le tableau 2. Le taux de $20 \mathrm{p}$. Ioo de matières grasses par rapport à la matière sèche a été choisi, car c'est celui qui nous avait donné les meilleurs résultats au cours d'un essai antérieur où nous avions distribué à des veaux entre 40 et I20 kg, trois aliments d'allaitement contenant respectivement 15,20 et $25 \mathrm{p}$. I oo de suif. Les cinq aliments d'allaitement ont été fabriqués en deux étapes : dans un premier temps, un mélange de lait écrémé liquide et de matières grasses fondues ( $35 \mathrm{p}$. Ioo de la matière sèche) a été homogénéisé de manière à obtenir des globules gras d'un diamètre moyen de l'ordre de $2 \mu$, puis déshydraté dans une tour Spray ; dans un deuxième temps, la composition recherchée pour chaque aliment d'allaitement a été obtenue en mélangeant cette poudre de lait ainsi enrichie en matières grasses à de la poudre de lait écrémé ; les vitamines et la furazolidone ont été ajoutées au cours de la même opération.

Les aliments d'allaitement ont été dilués dans de l'eau à $40^{\circ} \mathrm{C}$ à raison de $\mathrm{I} 20 \mathrm{~g}$ de poudre pour $880 \mathrm{~g}$ d'eau et les laits ainsi obtenus, ainsi que le lait écrémé et le lait à $25 \mathrm{p}$. I 000, ont été distribués au seau deux fois par jour. Les quantités offertes étaient les mêmes pour tous les veaux ; elles étaient importantes et augmentaient avec l'âge, de $4 \mathrm{~kg} /$ jour à to jours, jusqu'à un maximum de $\mathrm{I} 6 \mathrm{~kg} / \mathrm{jour}$ à partir de 75 jours. Les quantités refusées par chaque veau étaient pesées après chaque repas. Les veaux n'ont consommé aucun autre aliment que ces laits ; ils ont donc été maintenus au stade préruminant jusqu’à leur abattage.

\section{Animaux}

Les essais ont été effectués sur Ig veaux mâles, parmi lesquels deux ont dû être retirés pour des raisons sanitaires. Ces animaux ont été mis en expérience en 3 séries successives de mars 1965 à août 1966 (tabl. 3). Ces veaux, de race Française Frisonne Pie-Noire, achetés à l'âge d'environ 7 jours, ont été placés, dès leur arrivée, dans des cages à bilan (BOCCARD et BoISSAU, I958). Les mesures n'ont commencé qu'une semaine plus tard, de façon à laisser les veaux s'adapter à leurs nouvelles conditions d'existence. Ces mesures ont alors été effectuées en 6 périodes successives de ro jours, séparées par des inter-périodes de 4 jours au cours desquelles on a augmenté progressivement les quantités offertes qui restaient ensuite constantes au cours de chacune des périodes. Les veaux étaient pesés à jeun, le matin au début de chaque période et le lendemain de la fin de la période, ainsi que le jour de leur abattage (entre 95 et roo jours). Un seul veau a reçu le lait partiellement écrémé à $25 \mathrm{p}$. 1000 de matières grasses car, pour ce régime, nous voulions seulement déterminer la digestibilité des différents acides gras, MATHIEU et BARRÉ (I964) ayant déjà étudié sa digestibilité globale. Chacun des 6 autres aliments a été distribué à 3 veaux, mais seules les fèces des 2 qui ont effectué la meilleure croissance ont été analysées.

\section{Collecte des excrétas et abattage}

Les fèces et l'urine de chaque veau ont été recueillies séparément et pesées tous les jours. Les fèces de chaque veau ont été séchées à $80^{\circ} \mathrm{C}$ dans une étuve à circulation d'air chaud et broyées chaque jour en totalité ; un échantillon moyen par période a été constitué.

Les prélèvements quotidiens d'une partie aliquote d'urine (le $\mathrm{I} / 2 \circ$, le $\mathrm{I} / 4 \circ \mathrm{ou}$ le $\mathrm{x} / 60$ suivant les périodes) ont servi à préparer l'échantillon moyen par période dont on a dosé l'azote.

Les veaux ont été abattus entre les âges de 95 et roo jours. La carcasse, les différentes parties de l'appareil digestif plein et vide et les dépôts adipeux périrénaux, péritonéaux et intestinaux ont été pesés. Une demi-carcasse d'un veau par régime a été disséquée; les muscles, le squelette et les dépôts adipeux ont été broyés séparément pour constituer des échantillons moyens destinés à l'analyse.

\section{Méthodes d'analyse}

La teneur en matière sèche a été déterminée par séchage d'une part, à l'étuve à vide à $45^{\circ} \mathrm{C}$ pour les laits et les aliments d'allaitement et d'autre part, à $60^{\circ} \mathrm{C}$ pour les muscles hachés préalablement lyophilisés. La teneur en cendres a été déterminée par incinération au four à $55^{\circ} \mathrm{C}$ et la teneur en azote par la méthode Kjeldahl.

Le dosage des matières grasses a été effectué par la méthode de Folch, LeEs et SLOANE, STANLEY (1957) pour les laits, les aliments d'allaitement et les muscles lyophilisés. Le dosage des matières grasses et celui de l'eau des dépôts adipeux ont été faits par distillation azéotropique du benzène.

L'extraction des matières grasses des fèces pose un problème particulier, du fait de la présence de complexes insolubles formés au niveau intestinal. Afin de caractériser ces complexes, nous avons mis au point une méthode qui permet d'extraire séparémert les lipides non saponifiés et les acides gras des complexes insolubles (Toullec, Flanzy et Rigaud, 1968).

La composition en acides gras des différentes matières grasses a été déterminée par chromatographie en phase gazeuse des esters méthyliques et, également, des esters butyliques en ce qui concerne les matières grasses du lait. Les résultats sont exprimés en p. roo du total des esters méthyliques. 


\begin{tabular}{|c|c|c|c|c|c|c|c|c|c|}
\hline & \multicolumn{2}{|c|}{ 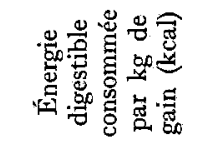 } & 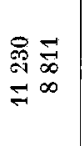 & 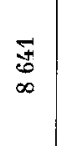 & $\begin{array}{l}8 \\
0 \\
\infty\end{array}$ & 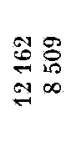 & $\begin{array}{l}5: \\
5 \\
\infty \\
\infty \\
\infty \\
\infty\end{array}$ & 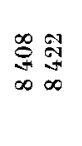 & 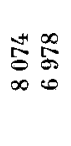 \\
\hline \multirow{10}{*}{ 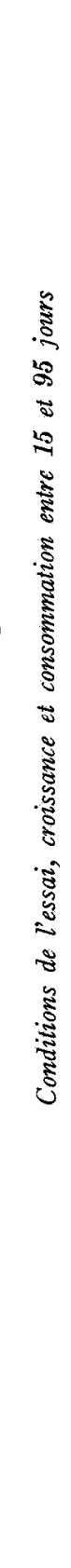 } & \multirow{2}{*}{ 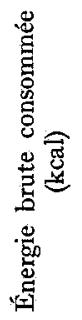 } & 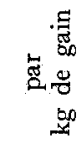 & 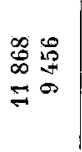 & $\begin{array}{l}\infty \\
\infty \\
\infty \\
\infty\end{array}$ & 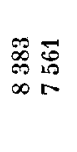 & 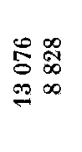 & 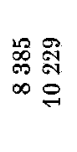 & 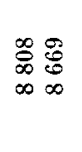 & 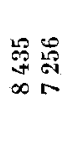 \\
\hline & & 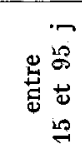 & 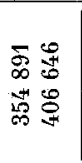 & 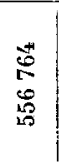 & 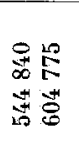 & 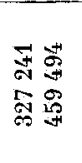 & 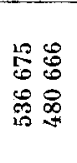 & 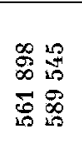 & 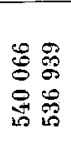 \\
\hline & \multirow{2}{*}{ 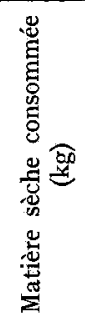 } & 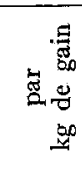 & ज̂ जी & $=$ & $\stackrel{0}{\rightarrow} \stackrel{*}{=}$ & $\stackrel{2}{=}=$ & $\stackrel{0}{=}$ & $\Rightarrow$ & $\stackrel{0}{\sim} \stackrel{+}{\sim}$ \\
\hline & & 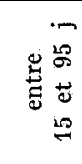 & $\begin{array}{l}\infty 0 \\
\hat{\tilde{O}} \\
\hat{\delta}\end{array}$ & के & $\stackrel{+\infty}{\stackrel{\infty}{\rightarrow}=}$ & 정 & $\hat{\sigma}_{0}^{\infty}$ & 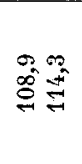 & 量密 \\
\hline & \multicolumn{2}{|c|}{ 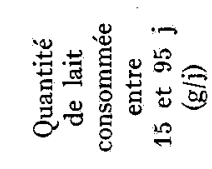 } & 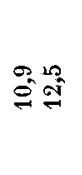 & $\Leftrightarrow$ & $\overrightarrow{=}=\overrightarrow{\mathrm{I}}$ & 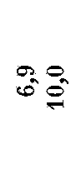 & $\stackrel{\infty}{\Leftrightarrow} \stackrel{\infty}{=}$ & $\stackrel{\infty}{=} \stackrel{5}{=}$ & $=$ \\
\hline & \multicolumn{2}{|c|}{ 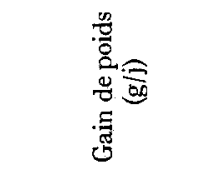 } & 鬲盒 & $\stackrel{\infty}{\circ}$ & $\frac{9}{\infty} \stackrel{g}{\square}$ & 的员 & 号品 & $\underbrace{\circ}_{\infty}$ & \& \\
\hline & \multicolumn{2}{|c|}{ 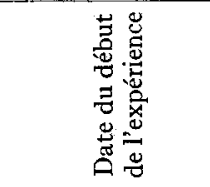 } & \multicolumn{3}{|c|}{ 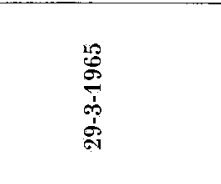 } & \multicolumn{3}{|c|}{$\frac{18}{\mathscr{8}}$} & 总 \\
\hline & \multicolumn{2}{|c|}{ 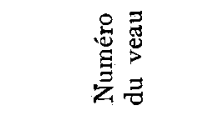 } & 路蛋 & 祲 & 突赵 & 象象 & 量量 & 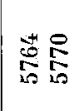 & $\frac{\infty}{8}$ \\
\hline & \multirow{2}{*}{\multicolumn{2}{|c|}{ 苞 }} & \multirow{2}{*}{ 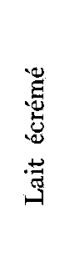 } & \multirow{2}{*}{ 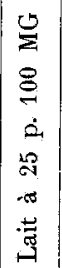 } & 苛 & 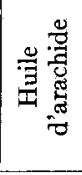 & 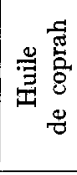 & 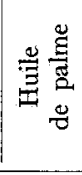 & 离 \\
\hline & & & & & & \multicolumn{4}{|c|}{ 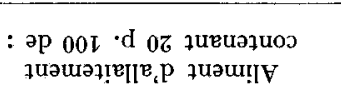 } \\
\hline
\end{tabular}




\section{RÉSULTATS}

\section{Croissance et état sanitaire}

Les veaux qui ont reçu les aliments contenant les matières grasses, sauf ceux qui ont ingéré l'aliment renfermant l'huile d'arachide, ont eu, en général, des gains de poids vif plus élevés que les veaux qui ont consommé le lait écrémé (tabl. 3). Ces différences étaient liées aux écarts entre les quantités de matière sèche et d'énergie consommées. En effet, la consommation de matière sèche des veaux qui ont reçu l'aliment contenant l'huile d'arachide a été inférieure de $29 \mathrm{p}$. Ioo à celle des animaux qui ont consommé les aliments contenant les autres matières grasses.

Pour caractériser la diarrhée, nous avons utilisé la classification basée sur la teneur en matière sèche des fèces proposée par BLAXTER et WOOD (I953), reprise par Roy et al. (I96I) et par MATHIEU et BARRÉ (I964). La fréquence des états correspondant aux différentes classes de matière sèche des fèces pour chaque régime apparaît dans la figure 2 . Les veaux qui recevaient le lait écrémé ont eu beaucoup plus souvent la diarrhée que les autres veaux $(60 \mathrm{p}$. Ioo de jours de diarrhée contre 5 à 2I p. Ioo avec les autres aliments : $P \leqslant 0,0 I)$. C'est avec l'huile d'arachide que la fréquence des diarrhées a été la plus élevée parmi les matières grasses étudiées.

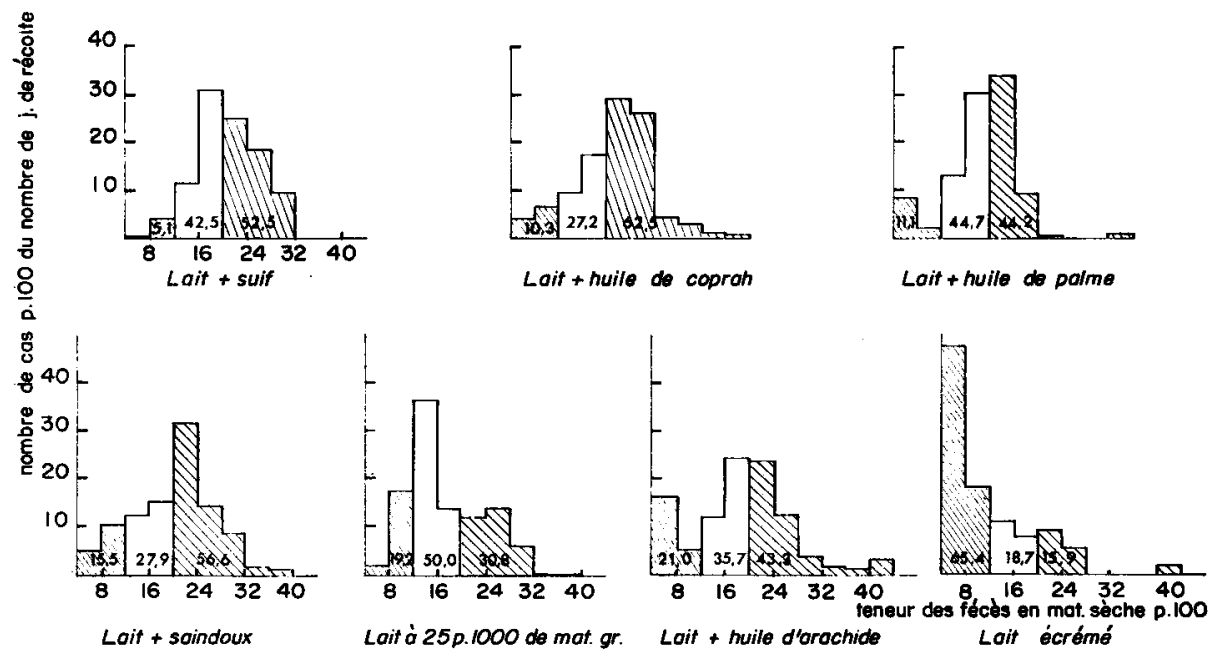

Fig. 2. - Répartition de la teneur en malière sèche des fèces (en p. Ioo du nombre de jours de récolte)

$$
\begin{aligned}
& \square \text { état " diarrhéique " } \\
& \square \text { état " relâché " } \\
& \square \text { état " normal " }
\end{aligned}
$$

\section{Digestibilité des matières grasses}

Matières grasses endogènes.

Les veaux alimentés au lait écrémé (moins de I $\mathrm{g}$ de matières grasses par $\mathrm{kg}$, donc pratiquement lipidoprive), excrètent une quantité d'acides gras très faible 
(de 0,3 à $2 \mathrm{~g}$ par jour) : elle ne varie ni avec 1'âge, ni avec la quantité d'aliment ingérée, mais augmente significativement $(r=+0,75)$ avec l'incidence des diarrhées (tab1. 4). Les valeurs normales correspondent à $0,3 \mathrm{~g}$ par jour, ce qui est négligeable et n'a aucune influence sur la digestibilité réelle des matières grasses. Cependant, ScRIBANTE et FAVARger (I954) et Buensod et Favarger (I956), ont indiqué que chez le rat l'excrétion fécale endogène semblait influencée par la nature et la quantité des matières grasses du régime : par rapport au régime lipidoprive, elle était abaissée à la suite de l'ingestion de matières grasses très digestibles (trilaurine, monoglycérides) et n'était augmentée que dans le cas de régimes contenant des matières grasses de très faible digestibilité (acides palmitique et stéarique purs). Mais, Fremman, Holme et ANNISON (I968) ont montré à l'aide d'acides gras marqués, interestérifiés avec des matières grasses naturelles, que la part de l'endogène dans les lipides fécaux était très forte chez des porcs ingérant des aliments contenant Io $p$. Ioo de matières grasses. Cependant, Cunningham et Loosir (I954) ont obtenu des valeurs du même ordre que nous chez des veaux recevant un régime semi-synthétique lipidoprive à base de caséine et de glucose, de même que RAVEN et RoBINson (I958, I959 et I960) chez des veaux recevant du lait écrémé seul et additionné de lactose ou d'amidon ; mais ces auteurs n'ont pas signalé de relation avec l'incidence des diarrhées.

\section{TABLEAU 4}

Excrétion fécale endogène d'acides gras chez les veaux qui ont reşu le lait écrémé

\begin{tabular}{|c|c|c|c|c|c|c|c|}
\hline & \multirow{2}{*}{$\begin{array}{l}\text { Numéro } \\
\text { du veau }\end{array}$} & \multicolumn{6}{|c|}{ Périodes } \\
\hline & & 1 & 2 & 3 & 4 & 5 & 6 \\
\hline $\begin{array}{l}\text { Acides gras (p. } 100 \\
\text { de la matière sèche } \\
\text { des fèces) }\end{array}$ & $\begin{array}{l}5730 \\
5731\end{array}$ & $\begin{array}{l}2,4 \\
2,5\end{array}$ & 3,4 & $\begin{array}{l}1,7 \\
2,9\end{array}$ & $\begin{array}{l}2,4 \\
1,7\end{array}$ & $\begin{array}{l}2,6 \\
1,6\end{array}$ & $\begin{array}{l}1,5 \\
1,2\end{array}$ \\
\hline $\begin{array}{l}\text { Quantité d'acides } \\
\text { gras excrétée } \\
\text { par jour (g) }\end{array}$ & $\begin{array}{l}5730 \\
5731\end{array}$ & $\begin{array}{l}1,2 \\
0,6\end{array}$ & 2,0 & $\begin{array}{l}0,3 \\
1,5\end{array}$ & $\begin{array}{l}0,3 \\
1,2\end{array}$ & $\begin{array}{l}1,1 \\
1,3\end{array}$ & $\begin{array}{l}0,5 \\
1,1\end{array}$ \\
\hline $\begin{array}{c}\text { Teneur en MS } \\
\text { des fèces (p. 100) }\end{array}$ & $\begin{array}{l}5730 \\
5731\end{array}$ & $\begin{array}{r}6,1 \\
11,6\end{array}$ & $\begin{array}{l}6,5 \\
8,4\end{array}$ & $\begin{array}{r}12,7 \\
8,1\end{array}$ & $\begin{array}{r}19,5 \\
3,6\end{array}$ & $\begin{array}{l}5,5 \\
5,5\end{array}$ & $\begin{array}{r}11,7 \\
6,2\end{array}$ \\
\hline $\begin{array}{l}\text { Nombre de jours de } \\
\text { diarrhée au cours } \\
\text { de la période }\end{array}$ & $\begin{array}{l}5730 \\
5731\end{array}$ & $\begin{array}{l}6 \\
4\end{array}$ & $\begin{array}{l}9 \\
9\end{array}$ & $\begin{array}{l}1 \\
6\end{array}$ & $\begin{array}{r}1 \\
10\end{array}$ & $\begin{array}{r}6 \\
10\end{array}$ & $\begin{array}{r}5 \\
10\end{array}$ \\
\hline
\end{tabular}

Les acides gras excrétés sont très riches en acides ramifiés et impairs ( $16 \mathrm{p}$. Ioo des acides gras totaux), ce qui pourrait être dû aux acides gras subsistant dans le lait écrémé ou laisserait supposer une origine ou tout au moins un remaniement bactérien important; en effet, EvRARD et al. ( $\mathrm{rg} 63$ ) ont montré qu'en régime lipidoprive, les lipides excrétés par des rats normaux étaient constitués en partie d'acides gras impairs et ramifiés qui étaient absents de ceux excrétés par des rats axéniques. 


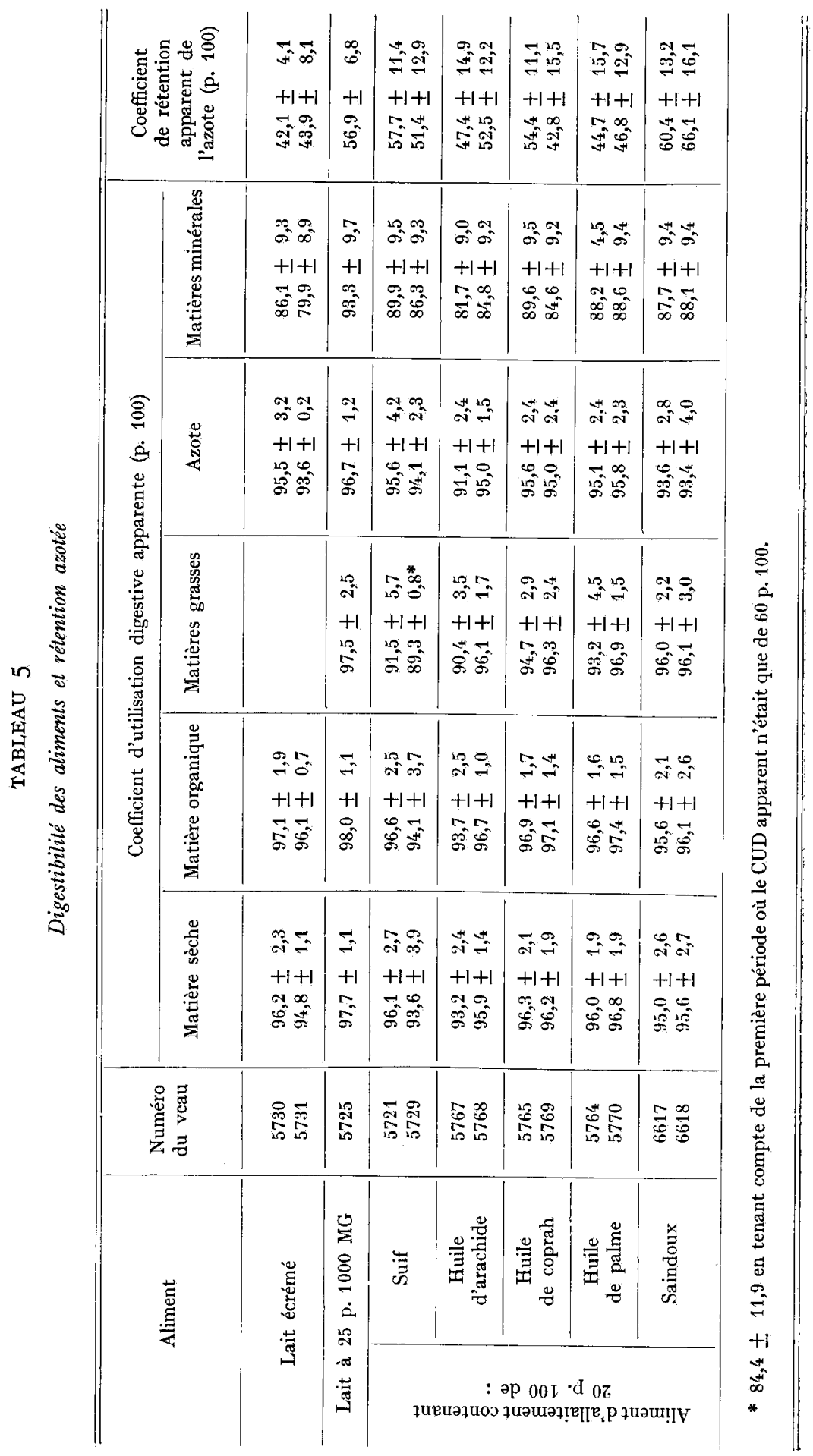


Digestibilité globale des matières grasses.

Toutes les matières grasses étudiées ont une digestibilité apparente élevée (tabl. 5) : suif 90 p. Ioo, huile d'arachide 93, huile de palme 95, huile de coprah et saindoux 96 et matières grasses du lait 98 . Seules sont significatives les différences entre suif d'une part et matières grasses du lait, saindoux, huiles de palme et de coprah d'autre part. Nos résultats sont du même ordre ou sont plus élevés que ceux obtenus par les autres auteurs pour les mêmes matières grasses (tabl. I).

La digestibilité des huiles de palme et de coprah ne varie pratiquement pas avec l'âge ; celle du suif et du saindoux augmente entre la première et la seconde période de mesures pour demeurer sensiblement constante ensuite; 1'évolution inverse se produit pour l'huile d'arachide (fig. 3). Cette évolution de la digestibilité des matières grasses riches en acides gras longs et saturés pourrait être due, notamment, à une sécrétion insuffisante de sels biliaires au début de la vie de l'animal.
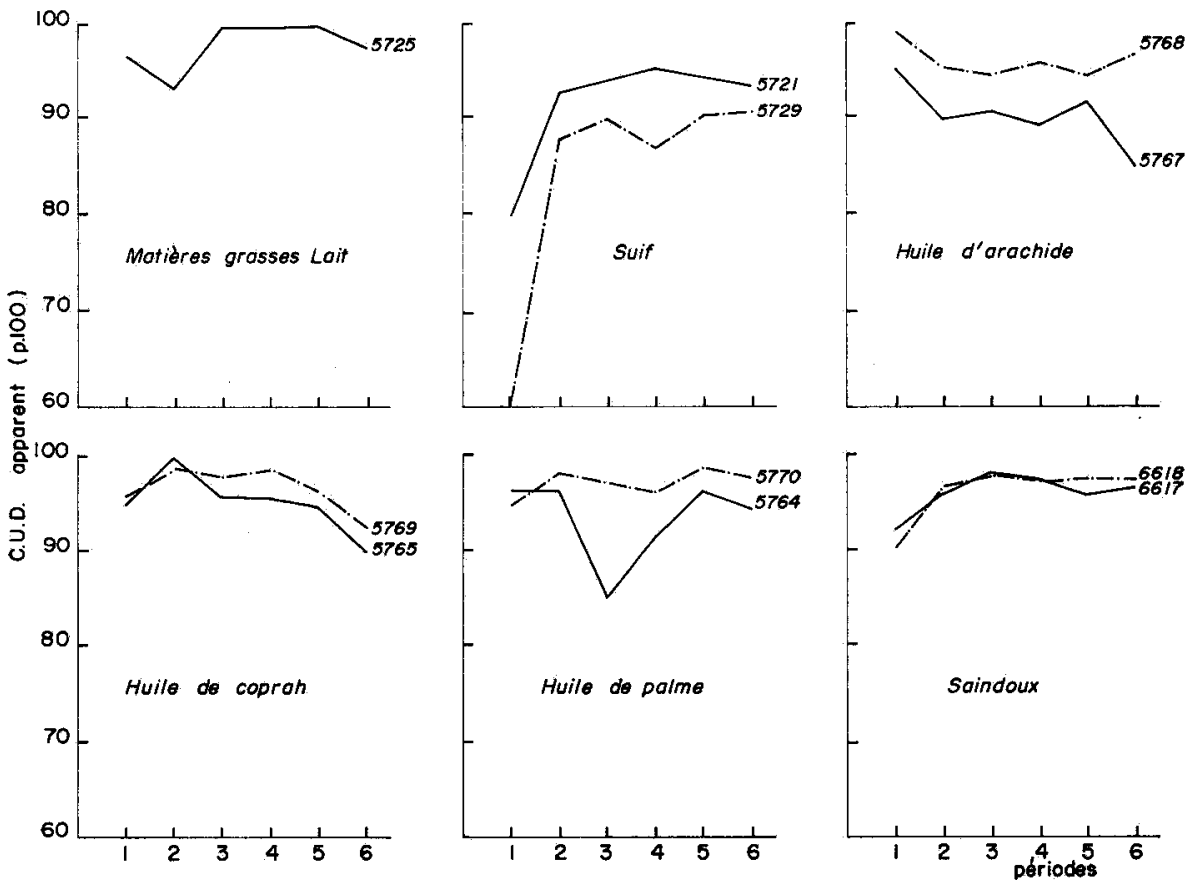

Fig. 3. - Évolution de la digestibilité des matières grasses avec l'âge

La digestibilité du suif est particulièrement faible chez l'un des veaux (no 5729), au cours de la première période de mesure (6o p. Ioo) et nous n'en avons pas tenu compte dans le calcul de la moyenne. Il y a des différences entre veaux dans le cas du suif, de l'huile de palme et de l'huile d'arachide (fig. 3). Dans ce dernier cas, le CUD apparent le plus faible est relié à une fréquence des diarrhées plus forte.

Digestibilité apparente des acides gras (tabl. 6).

La digestibilité apparente est pratiquement totale pour les acides gras courts jusqu'au $\mathrm{C}_{10}$; elle diminue pour les acides gras saturés en fonction inverse de la lon- 
gueur de chaîne; pour une même longueur de chaîne, elle augmente avec le degré d'insaturation. Ainsi, dans le cas du suif, les CUD apparents sont respectivement de 94,86 et $8 \mathrm{I}$ p. Ioo pour les acides myristique, palmitique et stéarique, et de 97 et Ioo p. Ioo pour les acides oléique et linoléique. La seule exception est observée chez les veaux qui ont reçu l'aliment d'allaitement contenant l'huile d'arachide : l'acide béhénique semble mieux utilisé que les acides stéarique et arachidique (respectivement $85,8 \mathrm{I}$ et $82 \mathrm{p}$. I0o). Cela ne saurait être attribué à la position de ces acides gras dans les molécules de triglycérides car ils sont tous trois en position externe (BROKERHOFF et YURKOWSKI, I966). Cependant, ces acides gras étant peu abondants dans l'huile d'arachide, cela pourrait être dû à l'imprécision des mesures.

\section{TABLEAU 6}

Coefficient d'utilisation digestive apparente des principaux acides gras

\begin{tabular}{|c|c|c|c|c|c|c|}
\hline & $\begin{array}{c}\text { Matières } \\
\text { grasses } \\
\text { du lait }\end{array}$ & Suif & $\begin{array}{c}\text { Huile } \\
\text { d'arachide }\end{array}$ & $\begin{array}{c}\text { Huile } \\
\text { de coprah }\end{array}$ & $\begin{array}{c}\text { Huile } \\
\text { de palme }\end{array}$ & Saindoux \\
\hline Acides gras totaux & 97,5 & 90,3 & 93,4 & 95,5 & 95,1 & 96,1 \\
\hline$<\mathrm{C}_{10} \ldots \ldots \ldots \ldots$ & 100,0 & & & 100,0 & & \\
\hline $\mathrm{C}_{10} \ldots \ldots \ldots \ldots \ldots$ & 100,0 & & & 99,1 & & \\
\hline $\mathrm{C}_{12} \ldots \ldots \ldots \ldots$ & 98,9 & & & 97,1 & & \\
\hline$c_{14} \ldots \ldots \ldots \ldots \ldots$ & 97,7 & 94,0 & & 93,8 & 93,2 & 97,6 \\
\hline $\mathrm{C}_{16} \ldots \ldots \ldots \ldots$ & 96,0 & 85,9 & 89,7 & 90,8 & 91,8 & 95,2 \\
\hline $\mathrm{C}_{18} \ldots \ldots \ldots \ldots \ldots$ & 95,6 & 81,4 & 81,3 & 85,3 & 89,4 & 90,6 \\
\hline$C_{18}: 1, \ldots \ldots \ldots$ & 98,8 & 97,0 & 95,7 & 96,0 & 98,6 & 98,2 \\
\hline$C_{18: 2}: \ldots \ldots \cdots$ & 100,0 & 100,0 & 97,9 & 98,5 & 99,6 & 99,4 \\
\hline $\mathrm{C}_{20} \ldots \ldots \ldots \ldots$ & & & 81,7 & & & \\
\hline $\mathrm{C}_{20}: 1 \ldots \ldots \ldots$ & & & 87,9 & & & \\
\hline $\mathrm{C}_{22} \ldots \ldots \ldots$ & & & 85,1 & & & \\
\hline $\mathrm{C}_{24} \ldots \ldots \ldots \ldots \ldots$ & & & 67,1 & & & \\
\hline
\end{tabular}

Ces différences de digestibilité entre les acides gras ont déjà été mises en évidence chez différents monogastriques (porc, rat, poulet...) soit avec des acides gras purs (CARROL, I958; CARROLL et RICHARDS, I958), soit avec des triglycérides homogènes ou mixtes (MatTiLL et HigGins, I945 ; SCRIBANTE et FAVARGER, I954), soit encore avec des matières grasses naturelles (RENNER et HILL, I95I ; BAYLEY et LEWIS, I965; FLANZY et al., I968). 
Les différences de digestibilité entre les acides gras sont d'autant plus fortes. que la digestibilité globale des matières grasses est moins élevée (4 p. Ioo entre les acides stéarique et linoléique dans le cas des matières grasses du lait, I9 p. Ioo dans le cas du suif).

La digestibilité des différents acides gras varie selon les matières grasses ingérées. Les variations sont surtout importantes dans le cas des acides gras longs et saturés. Leur digestibilité dépend de la proportion des acides gras courts ou insaturés qui les accompagnent : ainsi le CUD apparent de l'acide palmitique passe de $86 \mathrm{p}$. Ioo dans le suif (35 p. Ioo d'insaturés) à $90 \mathrm{p}$. Ioo (non significatif) dans l'huile de coprah $\left(5^{8} \mathrm{p}\right.$. roo d'acides gras $\left.<\mathrm{C}_{14}\right)$ et $92 \mathrm{p}$. Ioo $(p \leqslant 0,05)$ dans l'huile de palme (50 p. roo d'insaturés). Cela pourrait s'expliquer notamment par la solubilité micellaire plus grande des acides gras saturés et de leurs monoglycérides quand ils sont mélangés aux produits courts ou insaturés correspondants (HoFfmann, I966 ; Savary, I966). Cette hypothèse semble cependant infirmée par des travaux plus récents de SAVARY et ConstanTIN ( 1967 ) : ces auteurs ont indiqué qu'il y avait bien augmentation de la solubilisation micellaire de l'acide palmitique en présence de quantités croissantes d'acide oléique, mais seulement jusqu'au point de saturation des micelles, à partir duquel il y avait, au contraire, diminution.

La digestibilité des acides gras longs et saturés est également influencée par leur position dans les molécules de triglycérides ; ainsi, l'acide palmitique du saindoux qui est situé préférentiellement en position interne dans les molécules de triglycérides mixtes, a une digestibilité plus élevée (95 p. Ioo) que celui de l'huile de palme (92 p. IOo), mais la différence n'est pas significative. De même, chez le poulet, RENNER et HILI (I96I) ont observé une baisse de la digestibilité de l'acide palmitique du saindoux en le faisant passer de la position interne à une répartition au hasard par interestérification des triglycérides. Lors de 1'hydrolyse pancréatique, 1'acide palmitique du saindoux reste en grande partie sous forme de $\beta$-monoglycérides, ce qui favoriserait son absorption (MATTSON et VOLPENHEIM, I962) et limiterait davantage sa précipitation sous forme de complexes insolubles. Ainsi, Scribante et Favarger (I954) ont montré que l'acide stéarique a une digestibilité plus élevée sous forme de monostéarine que sous forme de triglycéride ou d'acide gras libre.

\section{Forme d'excrétion des matières grasses.}

La fraction insoluble a représenté une part variable mais souvent importante des acides gras des fèces (Toul_EC, Flanzy et Rigaud, I968). Elle est particulièrement élevée (70 p. Ioo) à la suite de l'ingestion de suif, et très faible chez les veaux qui ont reçu l'aliment d'allaitement contenant l'huile d'arachide (I4 p. IOo). Par conséquent, it faut en tenir compte dans les calculs de digestibilité. CunNIngham et Loosir (I954), AdAms et al. (I959) et Thomke (I963 $a$ et $b$ ) ont observé des proportions notables de savons dans les matières grasses excrétées par des veaux qui avaient reçu des aliments d'allaitement contenant du suif, du saindoux ou de l'huile de coprah hydrogénée. Cela a également été mis en évidence chez d'autres espèces comme le rat (CRocketT et DeUEL, I947; Carroli, et Richards, I958).

Dans tous les cas, les acides gras de la "fraction insoluble " sont plus longs et plus saturés que ceux de la "fraction soluble ": ainsi, les acides palmitique, stéarique et oléique constituent respectivement 33,37 et I 7 p. Ioo de la première fraction et 34,52 et $6 \mathrm{p}$. Ioo de la seconde, chez les veaux qui ont reçu l'aliment d'allaitement 
contenant le suif. Cela est surtout accentué chez les veaux qui ont reçu les aliments contenant le suif, le saindoux, l'huile d'arachide et 1'huile de palme, donc les matières grasses dépourvues d'acides gras courts. La digestibilité plus faible des acides gras longs et saturés semble donc due notamment à leur précipitation préférentielle dans 1a lumière intestinale sous forme de complexes insolubles. Ces formes insolubles seraient essentiellement constituées de savons de calcium d'après CaRROL, et RICHARDS (I958). Cependant, il n'y a pas de relation apparente entre les quantités de savons et de minéraux excrétés. Yacowitz et al. (I967) ont observé chez le rat une augmentation de la quantité de lipides fécaux avec l'élévation du taux de calcium du régime à la suite de l'ingestion de matières grasses ; avec du beurre de cacao (acides gras longs et saturés), l'augmentation était beaucoup plus forte qu'avec de l'huile de mais (acides gras insaturés) mais la quantité de calcium fécal était indépendante des matières grasses du régime.

\section{Digestibilité des autres constituants.}

Pour tous les régimes étudiés, le CUD apparent de la matière sèche, de la matière organique et de l'azote, reste relativement constant pendant toute la période expérimentale (tabl. 5). Les variations du CUD de la matière sèche et de la matière organique sont surtout dues à celles du CUD des matières grasses. Cependant, le CUD apparent des matières minérales varie dans des limites assez larges (écarts-types compris entre $\pm 4,5$ et $\pm 9,7$ ) sans que l'on puisse toutefois établir une relation entre ces variations et 1'âge des animaux. Le lait à $25 \mathrm{p}$. I ooo a la meilleure utilisation digestive.

\section{Rétention azotée.}

Le coefficient de rétention apparent de l'azote a d'abord tendance à augmenter avec l'âge, puis il passe par un maximum qui se situe généralement au début du second mois pour diminuer, par la suite, chez les veaux qui ont reçu le lait à 25 p. I 000

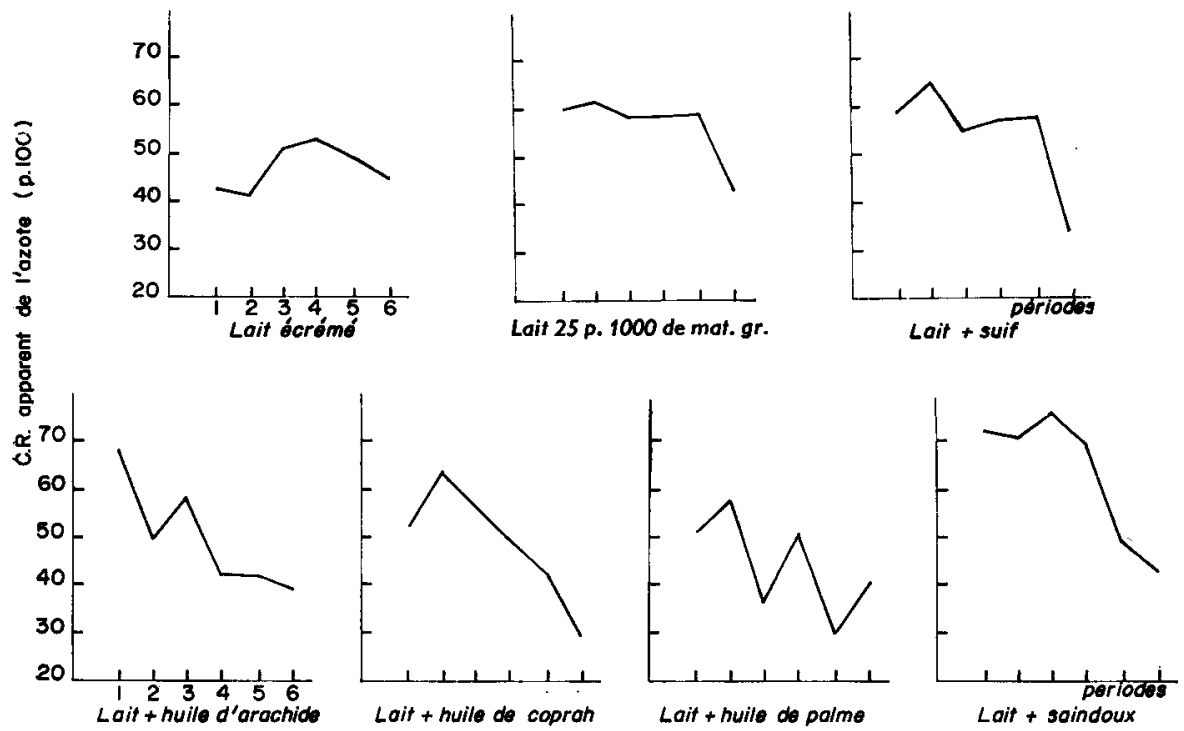

Fig. 4. - Évolution de la rétention apparente de l'azole avec l'âge 
et les aliments d'allaitement contenant le suif, le saindoux et les huiles de coprah et de palme (fig. 4). Avec le lait écrémé, l'évolution est irrégulière et avec l'aliment contenant 1'huile d'arachide, la tendance est toujours à la diminution avec l'âge. Les valeurs individuelles du coefficient de rétention présentent une corrélation significative $(P \leqslant 0,05)$ avec la quantité d'énergie digestible consommée par $\mathrm{kg}$ de gain de poids $(r=-0,62)$, mais la corrélation obtenue avec le gain de poids vif n'est pas significative $(r=+0,52)$. En revanche, la quantité d'azote retenue par période de mesure est significativement $(P \leqslant o, o r)$ reliée au gain de poids vif $(r=+0,43)$.

Le coefficient de rétention le plus élevé est obtenu avec l'aliment d'allaitement contenant le saindoux (63 p. I00) suivi par le lait à $25 \mathrm{p}$. I 000 (57), les aliments d'allaitement contenant le suif (55) et les huiles d'arachide (50), de coprah (49) et de palme (46) et enfin le lait écrémé (43). Remarquons cependant que pour le lait à 25 p. I 000, nous ne disposions que d'un seul animal ; or MATHIEU et BarRé (I964), expérimentant dans des conditions semblables, mais sur trois animaux pour ce régime, avaient obtenu un coefficient de rétention de 63 . Le coefficient de rétention élevé obtenu avec l'aliment contenant le saindoux est peut-être dû, notamment, au fait que cet aliment était le moins riche en azote (tabl. 2 ).

\section{Carcasse et composition corporelle.}

L a conformation de la carcasse estimée de façon subjective est d'autant meilleure que le gain de poids des animaux est plus élevé. La proportion de dépôts adipeux obtenue par dissection de la carcasse (tabl. 7) est très faible chez le veau qui a reçu le lait écrémé ( $\mathrm{r}, 6 \mathrm{p}$. Ioo du poids vif vide) et nettement plus élevée chez les autres

\section{TABLEAU 7}

Rendement (tous les veaux) et composition corporelle (un veau par régime)

\begin{tabular}{|c|c|c|c|c|c|c|c|c|}
\hline & \multirow{3}{*}{ Régime } & \multirow{3}{*}{$\begin{array}{c}\text { Rendement } \\
\text { vrai } \\
\text { (p. } 100 \mathrm{du} \\
\text { poids vif } \\
\text { vide) }\end{array}$} & \multicolumn{2}{|c|}{$\begin{array}{c}\text { P. } 100 \\
\text { de la carcasse }\end{array}$} & \multirow{3}{*}{$\begin{array}{c}\text { Dépôts } \\
\text { adipeux } \\
\text { (p. } 100 \mathrm{du} \\
\text { poids vif } \\
\text { vide) }\end{array}$} & \multicolumn{3}{|c|}{ P. 100 de la matière fraîche } \\
\hline & & & & & & \multirow{2}{*}{$\begin{array}{l}\text { Teneur en } \\
\text { matières } \\
\text { grasses des } \\
\text { dépôts } \\
\text { adipeux }\end{array}$} & \multicolumn{2}{|c|}{$\begin{array}{l}\text { Échantillon moyen } \\
\text { des muscles }\end{array}$} \\
\hline & & & Muscles & Os & & & $\begin{array}{c}\text { Teneur en } \\
\text { matières } \\
\text { grasses }\end{array}$ & $\begin{array}{c}\text { Teneur en } \\
\text { matière } \\
\text { sèche }\end{array}$ \\
\hline \multicolumn{2}{|c|}{ Lait écrẻmé............ } & 63,9 & 58,8 & 25,4 & 1,6 & 43,7 & 0,7 & 22,6 \\
\hline \multicolumn{2}{|c|}{ Lait à 25 p. $1000 \mathrm{MG} . \ldots}$. & 63,6 & 62,9 & 21,6 & 6,8 & 60,3 & 2,2 & 24,3 \\
\hline \multirow{5}{*}{ 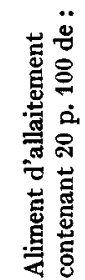 } & Suif............ & 64,3 & 61,4 & 20,1 & 6,1 & 86,9 & 2,1 & 23,9 \\
\hline & Huile d'arachide .. & 62,8 & $\mathbf{5 7 , 9}$ & 23,8 & 6,2 & 21,0 & 1,9 & 22,2 \\
\hline & Huile de coprah... & 63,2 & 59,5 & 21,8 & 8,9 & 51,7 & 1,9 & 22,2 \\
\hline & Huile de palme.... & 63,7 & 58,7 & 22,7 & 8,8 & 50,0 & 1,9 & 22,2 \\
\hline & Saindoux......... & 62,3 & 60,2 & 19,7 & 6,0 & 43,3 & 1,9 & 23,0 \\
\hline
\end{tabular}


animaux (entre 6 et 8 p. roo). La teneur en matières grasses de ces dépôts semble augmenter avec la teneur en acides gras longs et saturés des matières grasses ingérées ; elle est particulièrement faible chez le veau qui a reçu l'aliment d'allaitement contenant l'huile d'arachide ( $2 \mathrm{I}$ p. IOo), très élevée chez le veau qui a reçu l'aliment d'allaitement contenant le suif ( $86 \mathrm{p}$. Ioo) et intermédiaire chez les autres animaux (de 43 à 52 p. IOo). Il est cependant difficile de conclure à partir d'un seul animal disséqué par régime. La teneur en matières grasses de l'échantillon moyen de muscle est très faible chez l'animal qui a reçı le lait écrémé $(0,7 \mathrm{p}$. Ioo de la matière fraîche) et n'est pas beaucoup plus élevée chez les autres animaux ( $r, 9$ p. Ioo).

La composition en acides gras des graisses corporelles (dépôts, muscles et os) varie avec la nature des aliments (tabl. 8). Chez le veau qui a reçu le lait écrémé, les graisses corporelles sont essentiellement constituées d'acides palmitique, stéarique et oléique, respectivement 23,20 et 43 p. Ioo du total des acides gras des graisses des

\section{TABLEAU 8}

Composition en acides gras des graisses des dépôts (I), des muscles (2) et des os (3) (acides gras principaux p. Ioo du total des esters méthyliques)

\begin{tabular}{|c|c|c|c|c|c|c|c|c|c|c|}
\hline \multicolumn{2}{|c|}{ Régime } & & $\mathrm{C}_{10}$ & $\mathrm{C}_{12}$ & $\mathrm{C}_{14}$ & $\mathrm{C}_{16}$ & $C_{16}: 1$ & $\mathrm{C}_{18}$ & $\mathrm{C}_{18: 1}$ & $\mathrm{C}_{18}: 2$ \\
\hline \multicolumn{2}{|c|}{ Lait écrémé } & $\begin{array}{l}1 \\
2 \\
3\end{array}$ & & & $\begin{array}{l}2,8 \\
2,6 \\
1,8\end{array}$ & $\begin{array}{l}22,9 \\
20,4 \\
18,6\end{array}$ & $\begin{array}{l}4,0 \\
7,2 \\
6,5\end{array}$ & $\begin{array}{l}20,0 \\
13,4 \\
11,8\end{array}$ & $\begin{array}{l}43,0 \\
44,3 \\
54,2\end{array}$ & $\begin{array}{l}1,7 \\
3,5 \\
2,1\end{array}$ \\
\hline \multicolumn{2}{|c|}{ Lait à 25 p. 1000 de MG } & $\begin{array}{l}1 \\
2\end{array}$ & & 0,5 & $\begin{array}{l}7,8 \\
6,6\end{array}$ & $\begin{array}{l}30,6 \\
29,2\end{array}$ & $\begin{array}{l}5,0 \\
4,9\end{array}$ & $\begin{array}{l}14,1 \\
11,4\end{array}$ & $\begin{array}{l}31,2 \\
35,0\end{array}$ & $\begin{array}{l}1,3 \\
5,1\end{array}$ \\
\hline \multirow{5}{*}{ 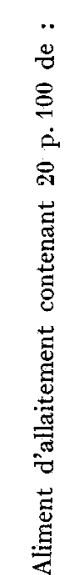 } & Suif & $\begin{array}{l}1 \\
2 \\
3\end{array}$ & & 1,2 & $\begin{array}{l}2,4 \\
1,8 \\
4,2\end{array}$ & $\begin{array}{l}23,1 \\
22,2 \\
24,7\end{array}$ & $\begin{array}{l}3,1 \\
4,8 \\
7,2\end{array}$ & $\begin{array}{c}23,2 \\
17,2 \\
10,7\end{array}$ & $\begin{array}{l}42,0 \\
45,0 \\
43,7\end{array}$ & $\begin{array}{l}1,7 \\
3,5 \\
1,4\end{array}$ \\
\hline & $\begin{array}{c}\text { Huile } \\
\text { d'arachide }\end{array}$ & $\begin{array}{l}1 \\
2 \\
3\end{array}$ & & & $\begin{array}{l}1,8 \\
1,3 \\
1,9\end{array}$ & $\begin{array}{l}15,5 \\
12,3 \\
15,8\end{array}$ & $\begin{array}{l}1,4 \\
4,1\end{array}$ & $\begin{array}{r}11,3 \\
8,3 \\
7,3\end{array}$ & $\begin{array}{l}57,7 \\
49,7 \\
63,8\end{array}$ & $\begin{array}{r}12,2 \\
17,9 \\
3,8\end{array}$ \\
\hline & $\begin{array}{c}\text { Huile } \\
\text { de coprah }\end{array}$ & $\begin{array}{l}1 \\
2 \\
3\end{array}$ & $\begin{array}{l}0,3 \\
2,2\end{array}$ & $\begin{array}{l}6,7 \\
6,5 \\
5,2\end{array}$ & $\begin{array}{l}24,1 \\
20,0 \\
17,2\end{array}$ & $\begin{array}{l}33,5 \\
28,5 \\
28,0\end{array}$ & 2,5 & $\begin{array}{r}10,6 \\
10,0 \\
8,5\end{array}$ & $\begin{array}{l}19,3 \\
20,0 \\
29,1\end{array}$ & $\begin{array}{l}1,2 \\
3,7 \\
2,4\end{array}$ \\
\hline & $\begin{array}{c}\text { Huile } \\
\text { de palme }\end{array}$ & $\begin{array}{l}1 \\
2 \\
3\end{array}$ & & & $\begin{array}{l}1,3 \\
1,7 \\
2,0\end{array}$ & $\begin{array}{l}\mathbf{2 5 , 5} \\
\mathbf{2 3 , 5} \\
21,3\end{array}$ & 2,7 & $\begin{array}{r}14,5 \\
12,5 \\
7,9\end{array}$ & $\begin{array}{l}48,2 \\
43,0 \\
55,7\end{array}$ & $\begin{array}{r}7,6 \\
14,1 \\
5,7\end{array}$ \\
\hline & Saindoux & $\begin{array}{l}1 \\
2 \\
3\end{array}$ & & & $\begin{array}{l}1,7 \\
1,8 \\
1,3\end{array}$ & $\begin{array}{l}21,3 \\
20,4 \\
20,9\end{array}$ & $\begin{array}{l}4,1 \\
4,5 \\
4,9\end{array}$ & $\begin{array}{l}17,2 \\
12,7 \\
11,0\end{array}$ & $\begin{array}{l}49,5 \\
49,4 \\
57,3\end{array}$ & $\begin{array}{l}4,9 \\
9,2 \\
2,9\end{array}$ \\
\hline
\end{tabular}

dépôts. Dans tous les autres cas, la composition en acides gras des graisses corporelles est nettement influencée par celle des matières grasses alimentaires, en particulier en ce qui concerne la teneur en acides gras insaturés. Ainsi, les teneurs en acides 
oléique et linoléique des graisses des dépôts sont beaucoup plus élevées chez le veau qui a reçu 1'huile d'arachide (58 et I $2 \mathrm{p}$. I0o) que chez celui qui a consommé le suif (42 et 2 p. IOo). Cependant, les acides gras courts $<\mathrm{C}_{12}$ ne sont pratiquement pas déposés ; 1'acide laurique de l'huile de coprah et des matières grasses du lait n'est que très partiellement stocké ( $44 \mathrm{p}$. Ioo dans 1'huile de coprah et seulement 7 p. too danles graisses des dépôts correspondants) tandis que l'acide myristique l'est plus largement, mais moins que les acides palmitique, stéarique et oléique. Mais la composition des graisses corporelles n'est pas non plus identique à celle des matières grasses alimentaires quand ces dernières ne contiennent que des acides gras longs. Chez le veau qui a reçu l'aliment d'allaitement contenant l'huile de palme, les teneurs en acides stéarique et oléique augmentent aux dépens de l'acide palmitique $(42 \mathrm{p}$. Ioo d'acide palmitique dans l'huile de palme et seulement 26 p. Ioo dans les graisses des dépôts). Chez les veaux qui ont reçu les aliments d'allaitement contenant le suif et le saindoux, seule la teneur en acide oléique augmente (aux dépens des acides palmitique et stéarique dans le premier cas, aux dépens du seul acide palmitique dans le second cas). Chez le veau qui a consommé l'huile d'arachide, l'acide palmitique et surtout l'acide stéarique sont relativement davantage déposés que les acides oléique et linoléique dont la somme constitue néanmoins $70 \mathrm{p}$. roo des acides gras des graisses des dépôts. Ces veaux semblent avoir davantage modifié les acides gras saturés alimentaires que les insaturés.

Quel que soit le régime alimentaire, les graisses des muscles sont les plus riches en acide linoléique $(P \leqslant 0,0 \mathrm{I})$; elles en contiennent en moyenne $8,7 \mathrm{p}$. IO0 $\pm 6,2$, alors que celles des dépôts et des os n'en renferment respectivement que $4,9 \pm 4,4$ et 3,I $\pm 3,4$ (différence non significative entre ces deux dernières). En revanche, les graisses des os sont les plus riches en acide oléique $(P \leqslant 0,0 I) \quad(50,6 \pm I 2,4$ au lieu de $4 \mathrm{I}, 9 \pm \mathrm{II}, 0$ et $43,3 \pm \mathrm{I} 3,0$ respectivement dans les graisses des muscles et des dépôts, la différence entre ces deux dernières n'étant pas significative). L'acide stéarique, au contraire, est plus abondant dans les graisses des dépôts $(P \leqslant 0,01)$ ( $\mathrm{I} 6, \mathrm{I} \pm 5,0$ au lieu de $12,4 \pm 3$,I et $9,5 \pm \mathrm{I}, 9$ respectivement, dans les graisses des muscles et des os, la différence entre ces deux dernières n'étant pas significative).

\section{DISCUSSION}

Le veau à l'engrais qui est maintenu au stade préruminant, se comporte physiologiquement comme un monogastrique. Ainsi, la digestibilité des acides gras varie avec la longueur de chaîne et le degré d'insaturation, comme cela a été observé chez le monogastrique. Il paraît donc logique que la digestibilité du suif soit la plus faible car c'est lui qui contient le plus d'acides gras longs et saturés, en particulier d'acide stéarique $(26 \mathrm{p}$. I0o). Cependant, le saindoux a la même digestibilité que l'huile de palme malgré une teneur en acide stéarique trois fois plus élevée, mais cela est sans doute lié à sa structure glycéridique particulière. La structure glycéridique des matières grasses du lait est peut-être également l'un des facteurs de leur très forte digestibilité. Un autre facteur susceptible de favoriser la digestibilité plus forte du saindoux, de 1'huile de palme et des matières grasses du lait par rapport au suif, est leur faible 
teneur en triglycérides entièrement saturés ; pour des matières grasses de composition en acides gras analogue à celles des nôtres, HILDITch et WILLIAMs (I964) citent une teneur de $27 \mathrm{p}$. Ioo en triglycérides trisaturés pour le suif, II p. Ioo pour le saindoux, Io $\mathrm{p}$. Ioo pour l'huile de palme et une teneur de $4 \mathrm{p}$. Ioo en dipalmitostéarine dans les matières grasses du lait. Or, l'acide stéarique est mieux absorbé par le rat sous forme de distéaromonoléine ou monostéarodioléine que sous forme de tristéarine + trioléine (Ma'Turi, et HrGGrNs, r945).

La digestibilité de l'huile d'arachide aurait dû être plus élevée que celle de l'huile de palme car elle est plus riche en acides insaturés. En fait, l'ingestion de l'aliment d'allaitement contenant l'huile d'arachide a augmenté l'incidence des diarrhées, en particulier chez l'un des veaux. Il semble que cette huile relativement insaturée soit mal utilisée au niveau métabolique car son ingestion prolongée entraîne un appétit limité, une vitesse de croissance réduite et des perturbations d'ordre digestif avec, comme conséquence, une baisse de la digestibilité. D'ailleurs, ce n'est qu'avec l'huile d'arachide que la digestibilité est plus forte au cours de la première période de mesure. Chez d'autres veaux qui avaient reçu alternativement deux aliments d'allaitement contenant de 1'huile d'arachide ou du suif, le CUD apparent de l'huile d'arachide se maintenait à 99 p. roo (résultats non publiés). C'est donc l'ingestion prolongée de cette huile qui a un effet néfaste. Il est possible que des phénomènes de toxicité ou de rancissement aient joué du fait de la pauvreté de l'aliment en vitamine E. Cependant, cette mauvaise utilisation des huiles insaturées par le veau a été observée par de nombreux auteurs avec des huiles plus insaturées que celle d'arachide : huiles de maïs, de coton et de soja (GULLICKson et al., I942 ; MURLEY et al., I949 ; ADAMs et al., I959), et pourrait être reliée à l'influence de leur composition en acides gras sur celle des graisses corporelles.

En effet, comme celles des monogastriques (LÉVy, I949), les graisses corporelles des veaux qui ont consommé les aliments contenant les matières grasses ont une composition en acides gras qui dépend de celle des matières grasses alimentaires, en particulier en ce qui concerne la teneur en acides gras insaturés (tabl. 8). Cela s'accorde avec les résultats obtenus sur le veau par HoFlund, HolmbERg et SELMANN (I956), ERWIN et STERNER (I963) et NiESAR (I965). Le veau traditionnel avait des graisses corporelles de composition à peu près constante (ToULLEC et RIGAUD, I966), car il ne recevait que du lait, dont les matières grasses ont une composition qui ne varie que dans les limites bien connues. Mais avec l'utilisation des matières grasses de substitution, les graisses corporelles du veau peuvent avoir une composition très variable, à l'inverse de celles du ruminant adulte dont la composition est relativement stable par suite de l'hydrogénation des acides gras alimentaires dans le rumen (cf. revue de GARTon, I959). D'ailleurs, nous avons pu observer que la composition en acides gras des lipides de la lymphe du canal thoracique était très proche de celles des matières grasses alimentaires (TOULLEC, I968). Cependant, les graisses corporelles n'ont pas une composition absolument identique à celle des matières grasses alimentaires. L,es mécanismes métaboliques tendent à maintenir une certaine constance des propriétés physiques des graisses corporelles (Tove, I960) ; il semble qu'à cet égard, le veau préruminant soit suffisamment capable de métaboliser les acides gras courts (matières grasses du lait et huile de coprah) et les acides gras longs saturés $\left(C_{16}\right.$ de 1 'huile de palme) ; en revanche, il n'utiliserait ou ne transformerait que très mal les acides gras 
insaturés (huile d'arachide). L'appétit et la vitesse de croissance limités observés à la suite de l'ingestion de l'huile d'arachide pourraient être dus à une utilisation trop importante de cette huile pour la production de chaleur, l'animal se défendant ainsi contre un envahissement de son organisme par les acides gras insaturés : ainsi, chez le Papio ursinus, SAVAGE et GolDSTONE (1965) ont observé une consommation d'oxygène plus élevée quand les matières grasses alimentaires étaient insaturées. HoPKINS, MurRay et CAmprelL (1955) ont indiqué que chez le rat mâle, l'appétit et le gain de poids étaient d'autant moins élevés que les acides gras saturés et monoinsaturés alimentaires étaient dans un rapport plus éloigné que celui observé dans les graisses des dépôts formés à la suite de l'ingestion d'aliments pauvres en matières grasses. De même, CRAIG et al. (1963) et BEARE et al. (1963) ont attribué le faible appétit et la médiocre vitesse de croissance de rats recevant des régimes riches en huile de colza, à la faible teneur de cette huile en acides saturés, particulièrement en acide palmitique.

Les acides gras courts ne sont que très peu déposés, ce qui confirmerait leur utilisation rapide à des fins énergétiques (BoL_INGER, 1965). Il semble donc que les matières grasses riches en acides gras courts qui sont rapidement métabolisés devraient favoriser la croissance au début de la vie du veau, d'autant plus qu'elles ont alors une utilisation digestive nettement plus élevée que les matières grasses riches en acides gras longs et saturés. En revanche, ces dernières devraient se révéler favorables à l'engraissement, car les acides gras longs et saturés sont métabolisés beaucoup moins rapidement.

En définitive, les principaux facteurs déterminant l'utilisation digestive des matières grasses chez le veau sont, d'abord la teneur en acides gras longs et saturés, particulièrement en acides gras $>\mathrm{C}_{16}$, et ensuite la position de ces acides gras dans les molécules de triglycérides. L'interestérification permet de modifier ce dernier facteur mais, c'est un procédé coûteux. On peut plus facilement obtenir une composition favorable en acides gras en mélangeant différentes matières grasses. Le suif, matière grasse employée classiquement en France pour des raisons économiques a une utilisation digestive satisfaisante, malgré sa teneur élevée en acides gras longs et saturés. Cependant, techniquement, il serait possible, et sans doute souhaitable, de le remplacer, au moins en partie, dans les aliments d'allaitement par des matières grasses contenant des acides gras courts, en particulier, au cours des premières semaines.

Reçu pour publication en novembre 1968.

\section{SUMMARY}

DIGESTIVE UTILIZATION OF FATS AND THEIR PRINCIPAL FATTY ACIDS

BY FATTENING PRE-RUMINANT CALVES.

INFLUENCE ON BODY COMPOSITION

The aim of the trial was to study digestive utilization by pre-ruminant calves of fats in relation to their fatty acid composition and their glyceride structure. Five fats, tallow, lard, and groundnut, coconut and palm oils were mixed with liquid skimmed milk at 20 per cent of the dry matter. The mixtures thus obtained were homogenized and then spray-dried (table 2). The milks prepared from these feeds were compared with half-skimmed milk, which had the same fat content, 2.5 per cent, and with 
fully skimmed milk, less than 0. I per cent fat, which could be considered practically lipid-free. The feeds were given to I 3 male Friesian calves, 2 per diet except for that with 2.5 per cent fat, which was given to only one calf (table 3 ). The calves were kept in metabolism cages from 8 to 95 days of age. The calves were given large amounts of the milks increasing with age from $8 \mathrm{~kg}$ daily at 10 days to a maximum of $16 \mathrm{~kg}$ from 75 days ; these amounts are similar to those usually offered to fattening calves.

$\mathrm{I}^{\mathrm{O}}$ The calves fed on fully skimmed milk excreted very small amounts of fatty acids, 0.3 to $2.0 \mathrm{~g}$ per day, which did not vary with age of with amount of feed taken, but which increased with the frequency of diarrhœa (table 4).

$2^{\circ}$ Apparent digestibility of the fats was very high : tallow 9o, groundnut oil 93, palm oil 95, coconut oil and lard 96 and milk fat 98 per cent (table 6).

$3^{\circ}$ Apparent digestibility of short-chain fatty acids, $<\mathrm{C}_{12}$, was almost complete. It decreased progressively with increase of chain length in the saturated fatty acids, and with the same length of chain it increased with the degree of unsaturation ; apparent digestibility of myristic, palmitic, stearic, oleic and linoleic acids of tallow were $94,86,81,97$ and roo per cent, respectively (table 6).

$4^{\circ}$ Palmitic acid seemed to be utilized better when it occupied and inside position in the triglyceride molecules, as in lard.

$5^{\circ}$ A high degree of unsaturation, groundnut oil, increased the frequency of diarrhoea (fig. 2) and was unfavourable for growth (table 3 ).

$6^{\circ}$ The main factor determining the digestive utilization of the fats studied was the content of saturated long-chain fatty acids $>\mathrm{C}_{16}$.

$7^{\circ}$ The fatty acid composition of body fat, particularly the content of unsaturated fatty acids was markeldy influenced by that of the fat in the feed (table 8 ). On the other hand, the short and medium-chain acids were not deposited to any extent. So in this respect the pre-ruminant calf behaves as a functional monogastric.

$8^{\circ}$ The fats rich in short-chain fatty acids would favour growth at the beginning of the life of the calf, the more so since then they are utilized markedly better than fats containing only long-chain and saturated fatty acids. On the other hand the latter would later favour fattening.

\section{RÉFÉRENCESS BIBLIOGRAPHIQUES}

Adams R. S., Gander J. E., Gullickson T. W., Sauter J. H., 1959. Some effects of feeding various filled milks to dairy calves. II. Fecal characteristics and digestibility data. J. Dairy Sci., 42, I 552-1 599 .

BAYLEY H.S., LEWIS D., 1965. The use of fats in pig feeding. II. The digestibility of vario us fats and fatty acids. J. Agric. Sci., 64, 373-379.

Beare J. L., Campbell J. A., Youngs C. G., CRaig B. M., I 963 . Effects of saturated fat in rats fed rapeseed oil. Can. J. Biochem. Physiol., 41, 605-61 2.

Blaxter K. I., Wood W. A., 1953. Some observations on the biochemical and physiological events associated with diarrhoea in calves. Vet. Rec., 65, 889-892.

Boccard R., Boissau J. M., 1958. Modèle d'une cage à digestibilité pour petits ruminants. Ann. Zootech., 7, 89-95.

BOLLINGER J. N., REISER R., 1965. The metabolic fate of fatty acids derived from dietary triglycerides. J. Am. Oil Chem. Soc., 42, II $30-1 \mathrm{I} 33$.

BrockerhofF H., YuRKowsk1 M., I966. Stereospecific analyses of several vegetable fats. J. Lipid Res., 7, 62-65.

Bruggemann J., Barth K., 1959. Die abhängiket der Verdaulichkeit einiger nährstoffe vom alter des kalbes. Zeitschr. Tiersphys. Tierern. Fultermk., 14, 284-292.

Carrol K. K., 1958. Digestibility of individual fatty acids in the rat. J. Nutr., 64, 399-410.

Carrol K. K., Richards J. F., I958. Factors affecting digestibility of fatty acids in the rat. J.Nutr., 64, $4 \mathrm{II}-424$.

Craig B. M., Youngs C. G., Beare J. L., Campbell J. A., I963. Fatty acid composition and glyceride structure in rats fed rapeseed oil or corn oil. Can. J. Biochem. Physiol., 41, 43-49.

Craig B. M., Youngs C. G., Beare J. L., Campbell J. A., I963. Influence of selective and non-selective hydrogenation of rapeseed oil on carcass fat of rats. Can. J. Biochem. Physiol., 41, 51-56.

Crockets M. E., Deuel Jr H. J., 1947. A comparison of the coefficient of digestibility and the rate of absorption of several natural and artificial fats as influenced by melting point. J. Nutr., 38, 369-379.

Cunningiam H. M., Loosli J. K., 1954. The effects of fat free diets on young dairy calves with observations on metabolic fecal fat and digestion coefficients for lard and hydrogenated coconut oil. J. Dairy Sci., 37 , 453-46r. 
Drmick P. S., Mc Carthy R. D., Patton S., 1965. Structure and synthesis of milk fat. VIII. Unique positional of palmitic acid in milk fat triglycerides. $J$. Dairy $S c i$., 48, 735-736.

Erwin E. S., Sterner W., 1963. Dietary lipids and fatty acids deposition in various calf tissues. Amer. J. Physiol., 205, I I 5 โ-1 I53.

Evrard E., Hoet P. P., Eyssen H., Charlier H., Sacquet E., ig64. Fecal lipids in germ-free and conventional rats. Brit. J. Exp. Pathol., 15, 409-4I4.

Fingerling G., 1908. Ersatz von vollmilch durch magermilch mit und ohne surrogatë bei sangkälbern. Landwirtsch. Versuchsstat., 68, $14:-188$.

Flanzy J., 1958. Communication personnelle.

Folch J., Lee 3 M., Sloane-Stanley G. H., 1957. A simple method for the isolation and purification of total lipids from animal tissues. J. Biol. Chem., 226, 497-509.

Freeman C. P., Holme D. W., Annison E. F., 1968. The determination of the true digestibility of interesterified fats in young pigs. (Abstr.). Proc. Nutr. Soc., 27, 13 A.

Garton G. A., I955. In Physiology of digestion in the ruminant. Edited by Dougherty R. N., Allen R. S., Burroughs W., Jacobson N. L., M Gilliard A. D., Butterworths, Washington.

Gullickson T. W., Fountaine E. C., Fitch J. B., i942. Various oils and fats as substitutes for butterfat in the ration of young calves. J. Dairy Sci., 25, I $17^{-1} 28$.

Haecker A. L., 1905. Nebr. Agr. Exp. Sta. Bul., 87, Cité par Delage J., Coleou J., I96r. No spécial de Rev. Fr. Corps gras. Journées d'études sur les corps gras dans lalimentation. Marseille.

Hamada T., Kameoka K., Morimoto M., r965. Studies on substitute milk containing dried skimmilk with tallow, lecithin or wheat for dairy calves. Agric. Biol. Chem., 29, 998-1003.

Hilditch T. P., Williams P. N., I964. The chemical constitution of natural fats. Chapman et. Hall. Londres.

Hoffmann A. F., I966. A physicochemical approach to the intraluminal phase of fat absorption. Gastroent., 50, 55-54.

Hoflund S., Holmberg J., Sellmann G., 1955. Investigations on fat digestion and fat metabolism in ruminants. II. Feeding insaturated fats to dairy calves. Cornell Veter., 46, 5 i-53.

Hopkins C. Y., MURRaY T. K., Campbell. J. A., I955. Optimum ratio of saturated to unsaturated fatty acids in rat diets. Can. J. Biochem. Physiol., 33, 1047-1054.

Hopkins D. T., Warner R. G., Loosli J. K., 1959. Fat digestibility by dairy calves. J. Dairy Sci., 42, $1815-1820$.

LÉVY M., I949. Influence de l'alimentation sur la composition des graisses de réserve. Journées scientifiques du CNERNA. Les corps gras alimentaires, 5, 6, 7 avril. Éd. du C. N. R. S., 249-275.

Matril K. F., Higgins J. W., I945. The relation of glyceride structure to fat digestibility. I. Synthetic glycerides of stearic and oleic acids. J. Nutr., 29, 255-260.

MathieU C.-M., BarRÉ P.-E., I964. Digestion et utilisation des aliments par le veau préruminant à l'engrais. I. Utilisation des laits entiers ou partiellement écrérnés. Ann. Biol. anim., Bioch. Biophys., 4, 403-422.

Mattson F. H., LutTon E. S., 1958. The specific distribution of fatty acids on the glycerides of animal and vegetable fats. J. Biol. Chem., 233, 868-87r.

Matrson F. H., Volpenheim R. A., i952. Rearrangement of glycerides fatty acids during digestion an absorption. J. Biol. Chem., 237, 53-55.

Murley W. R., Jacobson N. L., Wise G. H., Allen R. S., I 949. Filled milks for dairy calves. II. Comparative effects of various types of soybean oils and butter oil on health, growth, and certain blood constituents. J. Dairy Sci., 32, 609-5r 9 .

NizsaR K. H., I 965 . Untersuchungen zum einfluss von futterfetten auf das fettsäuremuster der organlipide landwirtschaftlicher nutztiere. Zblt. Veterinärmedizin., 12 A, 589-652.

Raven A. M., Robinsox K. L., 1958. Studies on the nutrition of the young calf. I. A comparizon of starch, lactose, and hydrogenated palm oil, with butterfat, in milk diets. Brit. $J$. Nutr., 12, 469-482.

RAVEN A. M., Robinson K. L., I 959 . Studies on the nutrition of the young calf. II. The nutritive value of unhydrogenated palm oil, unhydrogenated palm-kernel oil, and butterfat, as additions to a milk diet. Brit. J. Nutr., 13, 178 -1 90.

Raven A. M., Robinson K. L., Ig6o. Studies on the nutrition of the young calf. III. A comparison of unhydrogenated palm.-kernel oil, hydrogenated palm-kernel oil and butterfat as constituents of a milk diet. Brit. J. Nutr., 14, I 35-146.

Raven A. M., Robinson K. L., ig64. Factors affecting the nutritive value of fat for calves. J. Sci. Fd Agric., 15, 214-227.

Renner R., Hill F. W., r $96 \mathrm{I}$. Factors affecting the absorbability of saturated acids in the chick. J. Nutr., 74, 254-258.

Roy J. H. B., Shillam K. W. G., Thompson S. Y., Dawon D. A., 196r. The effect of emulsification of a milk substitute diet by mechanical homogeneisation and by the addition of soyabean lecithin on plasma lipid and vitamin A levels and the growth rate of the newborn calf. Brit. J. Nutr., 15, 541-554.

Savage N., Goldstone B. W., I965. Effects of different dietary fats on oxygen consumption and serum lipid level in the baboon. Brit. $J$. Nutr., 19, 459-468. 
Savary P., Flanzy J., Desnuelle P., i957. Emploi de la lipase pancréatique pour l'étude de la structure des corps gras naturels. Biochim. Biophys. Acta, 24, 4I4-423.

SAvary S., 1966. Sur la solubilisation micellaire des acides palmitique, stéarique et oléique dans les solutions d'acides biliaires conjugués. Biochim. Biophys. Acta, 125, 328-334.

Savary P., Constantin J. M., I 967 . Sur la solubilisation micellaire de l'hexadécane et son passage dans la lymphe thoracique du rat. Biochim. Biophys. Acta, 137, 264-276.

Scribante P., Favarger P., I954. Étude de la digestibilité de l'acide stéarique et de ses esters glycéridiques chez le rat. Helv. Pharmacol. Acta, 12, 74-89.

Tномке S., 1963. Die Verdaulichkeit van Vollmich und milchaustausfuttermitteln mit Zusatz eines rindertalg-schmalz-gemisches bzw. von Knochenfett. Züchtungskunde, 35, 214-231.

Tномке S., I963. Die Verdaulichkeit von Knochenfett und rindertalg zwei verschiedener partikalgrössen. Züchtungskunde, 35, 268-278.

Toulıec R., I968. Absorption des matières grasses par la voie lymphatique chez le veau préruminant. Ann. Biol. anim., Bioch. Biophys., 8, 445-447.

Toullec R., Flanzy J., Rigaud J., r 968 . Dosage des lipides des fèces : extraction séparée, importance et composition en acides gras des lipides non saponifiés et de ceux des complexes insolubles. Ann. Biol. anim., Bioch. Biophys., 8, 281-289.

Toullec R., Rigaud J., i 966 . Influence de la source d'énergie de la ration sur la composition de quelques dépôts adipeux chez le veau préruminant à l'engrais. Rev. Fr, Corps gras, 13, 535-54I.

Tove S. B., I960. The origin of depot fat. J. Dairy Sci., 43, I 354-1 360.

Yacowitz H., Fleischman A. I., Amsden R. T., Bierenbaum M. L., ig67. Effects of dietary calcium upon lipid metabolism in rats fed saturated or unsaturated fat. $J$. Nutr., 92, 389-392. 